\title{
Anaesthesia for Caesarean delivery in a patient with May- Hegglin anomaly
}

The anaesthetic management for Caesarean delivery is described in a patient with May-Hegglin anomaly. The condition, which is inherited as an autosomal dominant characteristic, has features of thrombocytopenia and a bleeding diathesis. Labour was induced and she received type specific platelet transfusion. Spinal anaesthesia, using five per cent lidocaine, $75 \mathrm{mg}$, with epinephrine and $0.5 \mathrm{mg}$ morphine sulphate produced satisfactory operating conditions, excellent postoperative analgesia, and uncomplicated initial recovery.

This case report reviews the anaesthetic implications and management of labour and Caesarean delivery in a parturient who presented with the May-Hegglin anomaly with resultant thrombocytopenia.

\section{Case report}

A 31-year-old primigravida, with previously diagnosed May-Hegglin anomaly, presented to our medical centre with spontaneous rupture of membranes at 41 weeks gestation. She had no history of bleeding during extraction of wisdom teeth, and had no previous surgery. Physical examination on admission revealed no abnormalities; admission haemoglobin was $13.9 \mathrm{~g} \cdot \mathrm{dl}^{-1}$, haematocrit was 41.2 per cent and platelet count $24,000 \mathrm{~mm}^{-3}$. Prothrombin time (PT), partial thromboplastin time (PTT) and bleeding time were normal.

After consultation with perinatology, haematology, neonatology and anaesthesiology, she wanted a trial of

\section{Key words}

ANAESTHESIA: obstetric; INHERITED DISEASE: May-Hegglin anomaly.

From the Department of Anesthesiology Cedars-Sinai Medical Center, Los Angeles, California.

Address correspondence to: Dr. M. Kotelko, Department of Anesthesiology, Cedars-Sinai Medical Center, 8700 Beverly Boulevard, Los Angeles, California 90048. labour. After monitoring for 24 hours, induction and augmentation of labour with IV oxytocin was initiated. Labour analgesia was partially achieved with IV meperidine and promethazine on three occasions. As she progressed to complete dilatation, some vaginal bleeding and clots $(100 \mathrm{ml})$ were noticed. Six units of type specific platelets were transfused. Three hours later her platelet count was $35,000 \mathrm{~mm}^{-3}$. Despite progressing to complete dilatation, she continued to have dysfunctional labour and the fetal vertex failed to descend. Consequently, she was prepared for primary Caesarean section.

After ECG and blood pressure monitoring were established, 100 per cent oxygen was given by face mask and an IV infusion of $1500 \mathrm{ml}$ lactated Ringer's solution was administered. A spinal anaesthetic using five per cent lidocaine $(75 \mathrm{mg}$ ) with 1:200,000 epinephrine and $0.5 \mathrm{mg}$ preservative-free morphine sulphate was administered atraumatically at the $\mathrm{L}_{3.4}$ interspace. The patient was tilted to the left and a sensory dermatome level of $T_{2}$ was obtained.

A primary low transverse Caesarean section proceeded uneventfully. A male infant was delivered with Apgar scores of 9 at one and five minutes. The patient's vital signs were stable throughout. No excessive surgical bleeding was evident, and estimated blood loss was 700 $\mathrm{ml}$. She was transferred to the recovery room and experienced excellent postoperative analgesia for 22 hours from the subarachnoid morphine. She had mild facial itching, but no nausea, somnolence or respiratory depression. She walked 24 hours later and was discharged home on the fourth postoperative day without anaesthetic sequelae.

The infant had no complications while in the hospital. However, his platelet count was $41,000 \mathrm{~mm}^{-3}$ and, based on cytologic findings, was diagnosed as having MayHegglin anomaly.

Eighteen days postoperatively, the mother was admitted to the hospital with postpartum vaginal haemorrhage. Her haematocrit decreased from 37.0 to 28.9 per cent before her bleeding was effectively treated with IV fluid hydration, IV oxytocin and oral methergine. 


\section{Discussion}

The May-Hegglin anomaly is a rare hereditary disorder first described by May ${ }^{1}$ in 1909 . He noted the presence of giant platelets and blue inclusions in the cytoplasms of leukocytes in a peripheral blood smear of an asymptomatic young woman. In 1945, Hegglin $^{2}$ observed features of thrombocytopenia and a bleeding diathesis. Wassmuth et al. ${ }^{3}$ later confirmed autosomal dominant inheritance. It is suggested that the basic platelet defect results from impaired megakaryocyte fragmentation. ${ }^{4}$ Reported platelet counts in May-Hegglin anomaly have ranged from less than $10,000 \mathrm{~mm}^{-3}$ to normal levels, indicating variable expressivity. Sky-blue crescent-shaped inclusions are also seen in the cytoplasm of most neutrophils, basophils, eosinophils and monocytes.

The majority of patients are completely asymptomatic until bleeding occurs, affected patients usually presenting with epistaxis or purpura. Godwin and Ginsburg ${ }^{4}$ have shown that bleeding is the direct result of low platelet count and not platelet dysfunction. Tests of platelet function are usually normal, but bleeding time may be prolonged. $^{5}$

To the author's knowledge, there have been no published reports of the anaesthetic management of parturients with May-Hegglin anomaly. Two case reports of May-Hegglin anomaly and pregnancy have been described. Duff and Jackson $^{6}$ reported a patient who had May-Hegglin anomaly and Rhesus sensitization who required type-specific platelet transfusions prior to spinal anaesthesia for Caesarean delivery of a healthy but thrombocyotpenic infant. Gausis et $a l^{7}$ described a patient with May-Hegglin anomaly who had vaginal bleeding, generalized purpura and intrauterine fetal demise at 28 weeks gestation.

We chose spinal anaesthesia with the inclusion of preservative-free morphine over general anaesthesia for Caesarean delivery for a number of reasons: (1) she had never experienced severe bleeding during her lifetime; (2) the patient was very knowledgeable about her rare disorder, and she had a strong preference to be awake for the Caesarean delivery, and (3) although not specific to her case, a review of the literature indicated a very low incidence of haematoma after spinal anaesthesia. She had received six units of fresh donor specific platelets before surgery even though her PT, PTT and bleeding time were normal.

The reported occurrence of epidural venous puncture is 1.0 per cent with a spinal or epidural needle. ${ }^{8}$ Bearing this risk in mind, the patient preferred a regional anaesthetic. Postoperatively, she was observed closely for any neurological signs of cord compression secondary to epidural or spinal haematoma. In healthy patients the incidence of haematoma resulting in neurological deficit after spinal anaesthesia or lumbar puncture is extremely low. In a combined series totalling more than 50,00 spinal anaesthetics, ${ }^{9}$ no cases of spinal haematoma were reported. This risk may not be similar in our patient.

A recent literature review by Owens et al. ${ }^{9}$ reported 33 cases of spinal haematoma: six cases after spinal anaesthesia, and 27 cases after lumbar puncture for diagnostic or therapeutic purposes. Of the 33 patients, 26 had evidence of haemostatic abnormality: 13 had received anticoagulants, nine had thrombocytopenia. Forty-five per cent had partial or good recovery of neurological function.

For the patient with May-Hegglin anomaly, another possible danger is peripartum maternal haemorrhage. Before labour, bleeding time should be corrected by platelet transfusion. The life-span of transfused platelets in patients with May-Hegglin anomaly is normal.

As the May-Hegglin anomaly is an autosomal dominant characteristic, a thrombocytopenic fetus would be expected in one-half of pregnancies of parturients afflicted with the anomaly. A reasonable labour management plan may be to determine fetal platelet count by fetal scalp sample, and base the mode of delivery on the results. Scot ${ }^{10}$ believes that fetuses with ITP appear unlikely to experience intracranial haemorrhage during vaginal delivery if their platelet counts are above $50,000 \mathrm{~mm}^{-3}$. It is unknown whether this holds for infants with May-Hegglin disorder. In our case, the fetal vertex tolerated a long labour without intracranial haemorrhage.

In this report, our patient ultimately delivered by Caesarean section a thrombocytopenic but otherwise healthy infant. The immediate surgical and anaesthestic courses were uncomplicated for the parturient. The optimal management of such cases is not clear, however, because of potential risks of maternal and fetal haemorrhage. Finally, it is strongly recommended that women with May-Hegglin anomaly be delivered at a tertiary centre, to ensure immediate access to the specialized medical care necessary for a successful outcome in so complex a case.

\section{References}

1 May $R$. Leukocyteneinschulusse. Deutsche Arch Klin Med 1909; 96: 1-6.

2 Hegglin R. Gleichzeitige konstitutionelle veranderungen an neutrophilen und thrombozyten. Helv Med Acta 1945; $12: 439-40$.

3 Wassmuth DR, Hamilton HE, Sheets RF. May-Hegglin anomaly. JAMA 1963; 183: 737-40.

4 Godwin HA, Ginsburg AD. May-Hegglin anomaly: a 
defect in megakaryocyte fragmentation. Br J Haematol 1974; 26: 117-28.

5 Lusher JM, Schneider J, Mizukami I et al. The MayHegglin anomaly: platelet function; ultrastructure and chromosome studies. Blood 1968; 32: 950-61.

6 Duff $P$, Jackson MT. Pregnancy complicated by thesus sensitization and the May-Hegglin anomaly. Obstet Gynecol 1985; 65: 7S-10S.

7 Gausis $N$, Fortune DW, Whiteside MG. The May-Hegglin anomaly. Br J Haematol 1969; 16: 619-20.

8 Bromage PR. Epidural Analgesia. Saunders Company, Philadelphia, 1978; pp. 659-60.

9 Owens EL, Kasten GW, Hessel EA. Spinal subarachnoid hematoma after lumbar puncture and heparinization: a case report, review of the literature, and discussion of anesthetic implications. Anesth Analg 1986; 65: 1201-7.

10 Scott JR, Cruikshank DP, Kochenour NK et al. Fetal platelet counts in the obstetric management of immunologic thrombocyotpenic purpura. Am J Obstet Gynecol 1980; 136: 495-9.

\section{Résumé}

Une primipare porteuse d'un syndrome de May-Hegglin (thrombocytopénie et diathèse hémorragique), transmis par mode autosomal dominant se présenta d̀ l'hôpital en travail. On lui donna des oxytociques et on lui fit une transfusion de plaquettes de son groupe sanguin. Pour la césarienne, on pratique une anesthésie rachidienne en injectant $75 \mathrm{mg}$ de lidocaïne à cinq pour cent avec adrénaline et $0.5 \mathrm{mg}$ de stulfate de morphine. Les conditions opératoires et l'analgésie post-opératoire ont été tout à fait adéquates. 